University of Nebraska - Lincoln

DigitalCommons@University of Nebraska - Lincoln

Faculty Papers and Publications in Animal

Science

Animal Science Department

2005

\title{
Estimates of Genetic Parameters for Feed Intake, Feeding Behavior, and Daily Gain in Composite Ram Lambs
}

\author{
K. M. Cammack \\ University of Nebraska-Lincoln \\ Kreg A. Leymaster \\ University of Nebraska-Lincoln, kleymaster2@unl.edu \\ T. G. Jenkins \\ USDA-ARS, U.S. Meat Animal Research Center, Clay Center, NE \\ Merlyn K. Nielsen \\ University of Nebraska-Lincoln, mnielsen1@unl.edu
}

Follow this and additional works at: https://digitalcommons.unl.edu/animalscifacpub

Part of the Animal Sciences Commons

Cammack, K. M.; Leymaster, Kreg A.; Jenkins, T. G.; and Nielsen, Merlyn K., "Estimates of Genetic Parameters for Feed Intake, Feeding Behavior, and Daily Gain in Composite Ram Lambs" (2005). Faculty Papers and Publications in Animal Science. 514.

https://digitalcommons.unl.edu/animalscifacpub/514

This Article is brought to you for free and open access by the Animal Science Department at DigitalCommons@University of Nebraska - Lincoln. It has been accepted for inclusion in Faculty Papers and Publications in Animal Science by an authorized administrator of DigitalCommons@University of Nebraska - Lincoln. 


\title{
Estimates of genetic parameters for feed intake, feeding behavior, and daily gain in composite ram lambs ${ }^{1,2}$
}

\author{
K. M Cammack ${ }^{* 3}$, K. A. Leymaster $\dagger$, T. G. Jenkins $\dagger$, and M. K. Nielsen*4 \\ *Department of Animal Science, University of Nebraska, Lincoln 68583-0908; and \\ $\dagger$ ARS, USDA, U.S. Meat Animal Research Center, Clay Center, NE 69663-0166
}

\begin{abstract}
Our objective was to estimate genetic parameters for feed intake, feeding behavior, and ADG in composite ram lambs (1/2 Columbia, $1 / 4$ Hampshire, $1 / 4$ Suffolk). Data were collected from 1986 to 1997 on 1,239 ram lambs from approximately 11 to $17 \mathrm{wk}$ of age at the U.S. Meat Animal Research Center near Clay Center, NE. Feeding equipment consisted of an elevated pen with an entrance chute that permitted access to the feeder by only one ram lamb at a time, with disappearance of feed measured by an electronic weighing system. Ram lambs were grouped 11 per pen from 1986 to 1989, and nine per pen from 1990 to 1997. Data were edited to exclude invalid feeding events, and approximately $80 \%$ of the data remained after edits were applied. Traits analyzed were daily feed intake (DFI), event feed intake (EFI), residual feed intake (RFI), daily feeding time (DFT), event feeding time (EFT), number of daily feeding events (DFE), and ADG.
\end{abstract}

Feed intake traits of DFI and EFI had estimated heritabilities of 0.25 and 0.33 , respectively, whereas estimated heritability of RFI was 0.11 . Heritability estimates for feeding behavior traits, including DFT, EFT, and DFE, ranged from 0.29 to 0.36 . Average daily gain had an estimated heritability of 0.26 . Genetic correlations were positive between all pairs of traits, except for RFI and ADG, and that estimate was essentially zero. Phenotypic correlations were generally similar to genetic correlations. Genetic correlations were large (0.80) between DFI and ADG, intermediate between DFI and RFI (0.61) and between DFT and DFE (0.55), and low (0.17 to 0.31$)$ for the other pairs of traits, with the exception of RFI and ADG (-0.03). Genetic correlations between behavioral traits were greater than correlations between behavioral traits and measures of feed intake or ADG; however, selection for ADG and/or feed intake would be expected to cause some changes in feeding behavior.

Key Words: Average Daily Gain, Behavior, Feed Intake, Genetic Parameters, Sheep

(C2005 American Society of Animal Science. All rights reserved.

J. Anim. Sci. 2005. 83:777-785

\section{Introduction}

Feed is a major cost of sheep production, and improved conversion of feed into product is one approach to increasing the profitability of an enterprise. An assessment of opportunities to genetically improve feed conversion by selection requires estimates of heritabil-

\footnotetext{
${ }^{1}$ Mention of a trade name, proprietary product, or specified equipment does not constitute a guarantee or warranty by the USDA and does not imply approval to the exclusion of other products that may be suitable.

${ }^{2}$ A contribution of the Univ. of Nebraska Agric. Res. Div., Lincoln. Journal Series No. 14639. This research was supported in part by funds provided through the Hatch Act.

${ }^{3}$ Current address: Anim. Sci. Dept., Univ. of Missouri, Columbia 65211.

${ }^{4}$ Correspondence: A218 Animal Sciences (phone: 402-472-6406; fax: 402-472-6362; e-mail: mnielsen1@unl.edu).

Received October 29, 2004.

Accepted December 29, 2004.
}

ity of feed intake as well as genetic correlations between feed intake and other traits of economic importance. These genetic parameters provide the basic information to develop breeds by selection and can be used to predict expected rates of direct and correlated responses to selection. Although feed intake by individual sheep is expensive to record, it has been argued (James, 1986) that feed intake should be included in the selection objective even if it is not a component of the selection index. Despite the economic importance of feed intake in sheep, few estimates of heritability have been published (Gallivan and Sullivan, 1994; Francois et al., 2002; Snowder and Van Vleck, 2003).

We used an electronic feeding system to collect information on feed intake and feeding behavior of ram lambs. The system allowed for the collection of feed data on individual sheep in a group setting and also provided a means to study feeding behavior traits. Correlated responses of feeding behavior traits due to selection to improve feed conversion may be pertinent. Thus, the objective of this experiment was to estimate genetic 
Table 1. Number of ram lambs and mean inbreeding coefficient by year

\begin{tabular}{lrc}
\hline \hline Year & No. & $\begin{array}{c}\text { Mean inbreeding } \\
\text { coefficient, \% }\end{array}$ \\
\hline 1986 & 161 & 0.7 \\
1987 & 170 & 0.9 \\
1988 & 172 & 1.0 \\
1989 & 173 & 1.4 \\
1990 & 68 & 1.2 \\
1991 & 70 & 1.3 \\
1992 & 70 & 1.5 \\
1993 & 71 & 2.7 \\
1994 & 72 & 2.7 \\
1995 & 71 & 2.4 \\
1996 & 71 & 2.8 \\
1997 & 70 & 3.2 \\
Total & 1,239 & - \\
\hline
\end{tabular}

parameters for feed intake, feeding behavior, and $\mathrm{ADG}$ of ram lambs from a terminal-sire composite population.

\section{Materials and Methods}

\section{Population and Management}

Data were collected on ram lambs of a terminal-sire composite population at the U.S. Meat Animal Research Center near Clay Center, NE. The composite population was initiated by mating Columbia rams and Hampshire-Suffolk crossbred ewes (Leymaster, 1991). The $\mathrm{F}_{1}$ generation of composite lambs was born in 1980, 1981, and 1982 and was produced by 27 Columbia sires. Sires whose progeny in 1980 excelled for growth rate were used to produce lambs in 1981 and 1982 . The $\mathrm{F}_{2}$ progeny born from 1981 to 1984 were produced by $31 \mathrm{~F}_{1}$ sires. The $\mathrm{F}_{3}$ generation lambs were born from 1982 to 1987 and were produced by 27 randomly selected $F_{2}$ sires. Subsequent generations were not discerned. To maintain a relatively large effective population size, a similar number of structurally sound rams was randomly selected within sire groups, and matings among paternal half-sibs were avoided. Mean inbreeding coefficients for each year of the experiment are shown in Table 1, and mean inbreeding was $3.2 \%$ for 1997-born ram lambs.

Ewe and ram lambs had access to a pelleted, totalmixed creep diet $(2.90 \mathrm{Mcal} / \mathrm{kg}$ of DM, with $17.5 \% \mathrm{CP}$ on a DM basis; energy and protein were calculated from standard feed tables) beginning at approximately $14 \mathrm{~d}$ of age. At approximately 7 wk of age, lambs were weaned in groups. From 1986 to 1997, ram lambs were randomly selected within sire groups to be placed into Pinpointer (AIS/PLM, Cookeville, TN) units at approximately $10 \mathrm{wk}$ of age. After a 1-wk adaptation period in the Pinpointer units, ram lambs were generally weighed on a weekly basis from 11 to 17 wk of age. Feeding events (length of time and feed removed [measured to the nearest $4.54 \mathrm{~g}$ ]) were recorded during this 42-d trial. Ram lambs continued on the creep diet throughout the trial. All feed intake data are from measurements on an as-fed basis.

Eight Pinpointer units were located in an enclosed building, and each consisted of an elevated pen $(2.4 \times$ $4.6 \mathrm{~m}$ ) with a woven-wire floor, an entrance chute, a scale-feeder unit, and a microcomputer. The entrance chute permitted access for only one ram lamb at a time to the scale-feeder unit. A tag, hung on the neck of each ram lamb, transmitted a signal that identified the ram lamb as it entered the unit. This process allowed for measurement of feed intake by each ram lamb while penned in a group.

Ram lambs were assigned to pens so that distributions of 9-wk BW were similar across pens, and progeny of a sire were generally placed into multiple pens. A total of 149 different sires were represented across all years. Ram lambs were grouped 11 per pen from 1986 to 1989 , and nine per pen from 1990 to 1997, allowing full expression of daily feed intake (Jenkins and Leymaster, 1987). Pens were used twice per year from 1986 to 1989 , and once per year thereafter. Contemporary groups $(n=128)$ consisted of ram lambs within a pen at the same time.

\section{Data and Editing Rules}

Information recorded for each ram lamb included sire, dam, age of dam, and type of birth. Age of dam was organized into three categories of 1-yr-old, 2-yrold, and 3-yr-old and older dams. In a similar manner, type of birth was arranged into three categories: single, twin, and triplet and greater. Six editing "rules" were applied to the data set to identify raw records for either deletion or alteration. These rules or steps were as follows: 1) deletion of all records of ram lambs that did not complete the trial or were unhealthy; 2) deletion of nonpositive feed-intake measurements; 3) assignment of some unidentified feeding records to specific ram lambs and deletion of other unidentified records; 4) deletion of feeding event records with exceptionally large values for event feed intake; 5) deletion of feed records with excessive rates of feed intake; and 6) adjustment of time value for extremely long feeding events. These rules are reviewed in the following six paragraphs. We acknowledge some degree of subjectivity in formulating the rules for acceptable feed records.

Ram lambs were weighed seven times at weekly intervals during the time they were in Pinpointer units, except in 1989, when only six weights were recorded. Records of animals with their heaviest weight not being one of the final two weights were deleted from the data set. Weight loss was considered an indicator of health problems that decreased animal performance. Additionally, records of ram lambs that did not complete the 42-d trial were removed from the data set. For each year, the total number of ram lambs with feed intake data used in analyses after the previous editing pro- 
Table 2. Distribution of feed intake per individual feeding event in ram lambs group-housed in Pinpointer units

\begin{tabular}{lcc}
\hline \hline Range, $\mathrm{g}$ & $\%^{\mathrm{a}}$ & Cumulative $\%^{\mathrm{b}}$ \\
\hline$\leq-453.6$ & 0.11 & 0.11 \\
-449.1 to -226.8 & 0.04 & 0.15 \\
-222.3 to -90.7 & 0.07 & 0.22 \\
-86.2 to 0.0 & 17.64 & 17.86 \\
4.5 to 90.7 & 51.26 & 69.12 \\
95.3 to 226.8 & 20.58 & 89.71 \\
231.3 to 453.6 & 8.54 & 98.25 \\
458.1 to 907.2 & 1.57 & 99.82 \\
911.7 to $1,360.8$ & 0.08 & 99.90 \\
$>1,360.8$ & 0.10 & 100.00 \\
\hline
\end{tabular}

apercentage of feeding event records with feed intake within that range.

${ }^{b}$ Percentage of feeding event records with feed intake $=$ the upper limit of that range.

cesses were applied is shown in Table 1. Data collected on 1,239 ram lambs remained in the final data set.

In the raw data set, there were 864,960 feeding event records. Before editing feed intake records, event feed intake ranged from $-4,472$ to $18,561 \mathrm{~g}$. Table 2 contains a listing of percentages of records in ranges of event feed intake. The majority (51\%) of event feed intakes were between 4.5 and $90.7 \mathrm{~g}$. Additionally, approximately $21 \%$ of feed intake events were in the range of 95.3 to $226.8 \mathrm{~g}$. As seen in Table 2, $18 \%$ of event feed intake data were recorded as less than or equal to $0 \mathrm{~g}$, and thus were deemed not valid and removed.

Feed intake and time data were assigned to a unique identification if an animal removing feed was not identified. Failure of the equipment to identify animals could be attributed to various reasons, including missing tags, failed tags, and mechanical failure. When supported by documented causes (e.g., lost tags), these data were assigned to the appropriate ram lambs. Remaining unassigned data were removed from the data set.

Feeding events with greater than 1,360.8 $\mathrm{g}$ intake were extremely scarce (Table 2) and uncharacteristic of the observed feeding behavior. These event records were considered the result of mechanical errors, errors due to human acts, or animals raking feed out of the feeder, and were therefore deleted from the data set.

Event feeding time ranged from $15 \mathrm{~s}$ to over $9 \mathrm{~h}$ in the unedited feed intake records. Events of less than $15 \mathrm{~s}$ were not recorded. Table 3 contains a listing by percentages for ranges of event feeding time. A large percentage (26\%) of the event feeding times ranged from 15 to 99 s. Additionally, 57\% of the records were for event feeding times less than $300 \mathrm{~s}$. A time:feed ratio (s/ g) was calculated for each feeding event. It was assumed that an animal would require at least $1 \mathrm{~min}$ to consume approximately $90 \mathrm{~g}$ of feed, and at least $2 \mathrm{~min}$ to consume approximately $180 \mathrm{~g}$ of feed, etc. Thus, events with ratios less than 0.66 were considered highly uncharacteristic of typical feeding behavior, and were deleted from the data set. Only $0.2 \%$ of the records re-
Table 3. Distribution of time spent eating per individual feed event in ram labs group-housed in Pinpointer units

\begin{tabular}{lcc}
\hline Range, $\mathrm{s}$ & $\%^{\mathrm{a}}$ & Cumulative $\%^{\mathrm{b}}$ \\
\hline 15 to 99 & 26.13 & 26.13 \\
100 to 199 & 18.31 & 44.45 \\
200 to 299 & 12.49 & 56.94 \\
300 to 399 & 9.67 & 66.61 \\
400 to 499 & 7.61 & 74.23 \\
500 to 599 & 5.90 & 80.13 \\
600 to 699 & 4.57 & 84.70 \\
700 to 799 & 3.47 & 88.17 \\
800 to 899 & 2.65 & 90.81 \\
900 to 999 & 2.04 & 92.86 \\
1,000 to 1,999 & 6.46 & 99.32 \\
$>1,999$ & 0.68 & 100.00 \\
\hline
\end{tabular}

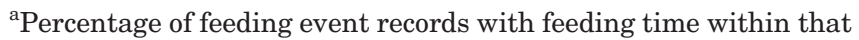
range.

${ }^{b}$ Percentage of feeding event records with feeding time $\leq$ the upper limit of that range.

maining after previous edits were deleted due to this criterion.

Feeding events with lengths greater than $2,400 \mathrm{~s}$ were considered to be valid for measurement of feed intake, but generally atypical of the animal in length of time. A total of $2,352(0.34 \%$ of the edited data set) feed intake records were greater than $2,400 \mathrm{~s}$, and the length of these records was set equal to 2,400 s. Extreme feeding lengths may be attributed to mechanical failure to record the animal's departure from the feeding chute or the animal remaining in the chute but not actively eating.

After all edits were applied, approximately $80 \%$ of the original data remained for analyses.

Daily feed intake and daily feeding time were computed for each ram on each day for which records were complete. Unfortunately, with various tag and mechanical failures, several daily records were lost or incomplete for most animals. Given that some daily feed records were missing and that daily feed intake increased as ram lambs grew, the 42-d trial was divided into three 14-d periods (d 1 to 14 , d 15 to 28 , and d 29 to 42 ) to approximate overall performance. Means of traits were calculated from available data for each 14-d period for each animal. These three period means were then averaged to represent the performance of individual ram lambs throughout the trial. By using the average of period means, each period mean was weighted equally across the 42-d trial for each ram lamb. In contrast, the mean of recorded data could be weighted more heavily to early, middle, or late periods of the trial for individual ram lambs due to missing data. The mean of the three period means was the characteristic analyzed; thus, any within-animal measurement error variance has been greatly reduced in any calculation of variability (SD or CV).

\section{Analyses}

Traits analyzed were daily feed intake, event feed intake, residual feed intake, daily feeding time, event 
feeding time, number of daily feeding events, and ADG. For each of these traits, only one record per animal was used. Average daily gain was calculated as the regression of BW on day of measurement during the test. Residual feed intake was the lack of fit for each animal's total feed intake ( $42 \mathrm{~d}$ ) from the model: total feed intake $=$ overall mean + contemporary group $+b_{m}$ (sum BW) $+b_{g}$ (total gain), where sum BW was the sum of daily BW, calculated as $42 \times$ (initial BW $+21 \times \mathrm{ADG}$ ), total gain was the difference in $\mathrm{BW}$ between the ending and starting weights for the 42-d trial, and $b_{m}$ and $b_{g}$ were the respective regression coefficients. Sum BW and total gain were continuous regression variables, and contemporary groups (year-pen groups) were fitted as fixed effects.

Multiple-trait, derivative-free restricted maximum likelihood (MTDFREML) procedures developed by Boldman et al. (1995) were used to obtain estimates of heritabilities and genetic and phenotypic correlations. The basic final model was $\mathbf{y}=\mathbf{X} \boldsymbol{\beta}+\mathbf{Z}_{\mathbf{a}} \mathbf{a}+\mathbf{Z}_{\mathbf{c}} \mathbf{c}+\mathbf{e}$, where $\mathbf{y}$ is a vector of observations corresponding to the trait(s) in the analysis, $\beta$ is a vector of fixed effects (type of birth and age of dam) for the trait, $\mathbf{a}$ is a vector of random animal genetic effects, $\mathbf{c}$ is a vector of random contemporary group effects, $\mathbf{e}$ is a vector of residuals, $\mathbf{X}$ is an incidence matrix relating observations to fixed effects, $\mathbf{Z}_{\mathbf{a}}$ is an incidence matrix relating observations to random animal genetic effects, and $\mathbf{Z}_{\mathbf{c}}$ is an incidence matrix relating observations to random contemporary group effects. The univariate version of this model has assumptions:

$$
\begin{gathered}
\mathbf{E}[\mathbf{y}]=\mathbf{X} \boldsymbol{\beta} \text { and } \\
\operatorname{Var}\left[\begin{array}{l}
\mathrm{a} \\
\mathrm{c} \\
\mathrm{e}
\end{array}\right]=\left[\begin{array}{ccc}
\mathrm{A} \sigma_{\mathrm{a}}^{2} & 0 & 0 \\
0 & \mathrm{I} \sigma_{\mathrm{c}}^{2} & 0 \\
0 & 0 & \mathrm{I} \sigma_{\mathrm{e}}^{2}
\end{array}\right]
\end{gathered}
$$

where matrix $\mathbf{A}$ is the numerator relationship matrix of all animals in the pedigree file, including those without records, and $\mathbf{I}$ is the identity matrix of appropriate order. The pedigree file included 12,096 animals and included the Columbia rams and Hampshire-Suffolk ewes used to produce the F1 composite lambs from 1980 to 1982.

Initial analyses of all traits included a random maternal genetic effect with possible covariance with the random animal genetic effect. For this expanded model, the maternal genetic effect was insignificant; thus, this effect was omitted from the final model used in analyses for all traits. Two-trait analyses were performed to estimate genetic and phenotypic correlations, fitting the same effects as for univariate analyses. Genetic correlations were computed by the MTDFREML program, and phenotypic correlations were computed from phenotypic (co)variances also from the MTDFREML program. Variance estimates derived in the two-trait analyses were very similar to those from the single-trait analyses.

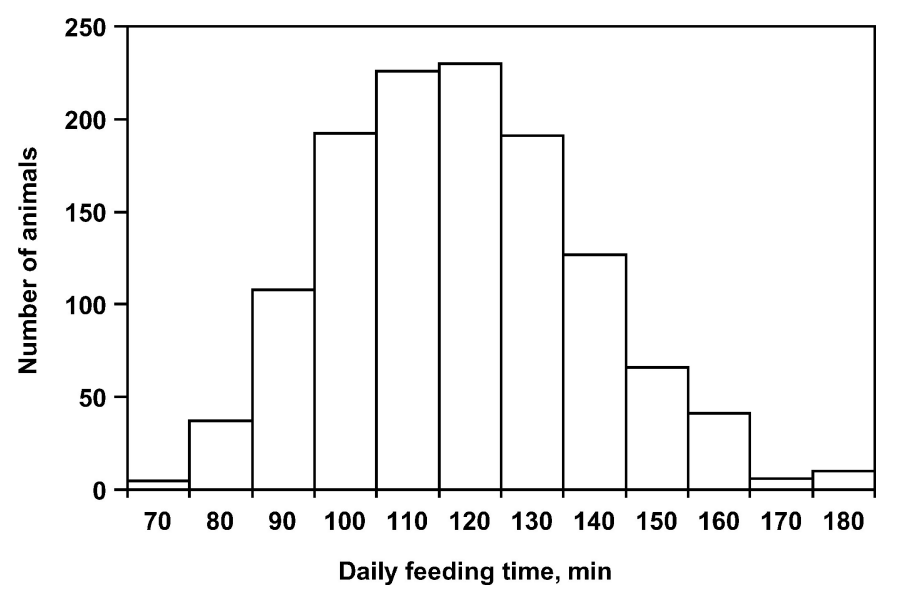

Figure 1. Distribution of average daily feeding time of 1,239 ram lambs. Data are given in ranges of $10 \mathrm{~min}$ with least being 65 to $75 \mathrm{~min}$ and the greatest $>175 \mathrm{~min}$. The most frequent range is 115 to $125 \mathrm{~min}$.

The GLM procedure in SAS (SAS Inst., Inc., Cary NC) was used to determine the effect of including age of dam, type of birth, both age of dam and type of birth, or neither in the models for single-trait analyses. Those fixed effects that decreased the residual error term in GLM analyses were subsequently included in MTDFREML models. Contrasts within age of dam and type of birth were performed in MTDFREML. Within age of dam, 1-yr-old dams were contrasted with 2-yrold dams and with 3-yr-old and older dams. Similarly, within type of birth, single births were contrasted with twin births and with triplet and greater births. Student's $t$-tests were used to determine significance of contrasts of fixed effects.

\section{Results and Discussion}

\section{Distributions}

Frequency distributions for daily feeding time, daily feed intake, and number of daily feeding events are shown in Figures 1, 2, and 3, respectively. Based on visual inspection, these three measures follow approximately normal distributions; however, none of the three distributions is normal $(P<0.01)$. Daily feed intake was skewed left, and all three distributions exhibited some degree of kurtosis with more frequent observations in the middle of the distributions than expected given the full range. Ninety-two percent of ram lambs had an average daily feeding time between 85 and $155 \mathrm{~min}$. The mean was $118.3 \mathrm{~min}$, and the most frequent 10 min range was 115 to $125 \mathrm{~min}$. The greatest-value class in Figure 1 was greater than 175 min, yet there were two animals with approximately 200 min for daily feeding time.

Distributions of daily feed intake and number of daily feeding events also had a few extremely large observations. We suspect that some of the large daily feed in- 


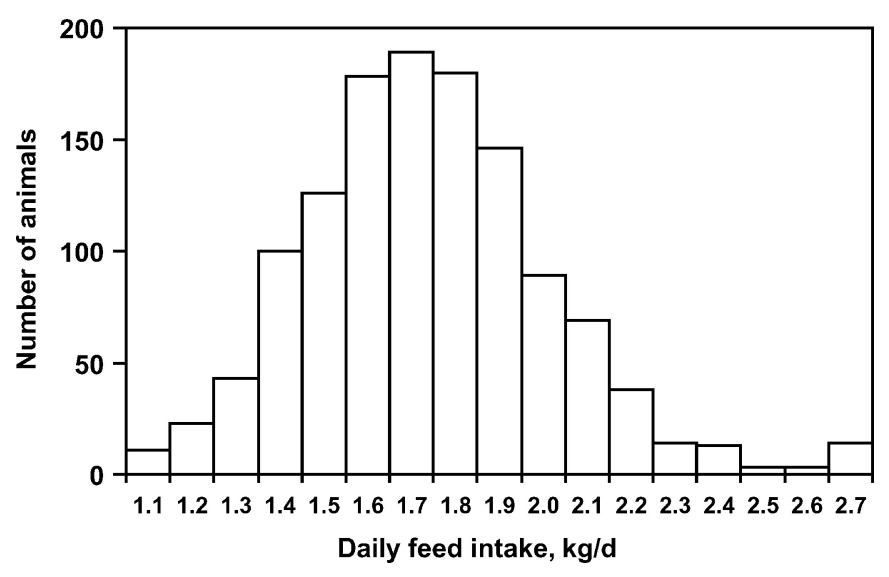

Figure 2. Distribution of ADFI (as-fed basis) of 1,239 ram lambs. Data are given in ranges of $0.10 \mathrm{~kg} / \mathrm{d}$ with least being 1.00 to $1.10 \mathrm{~kg} / \mathrm{d}$ and the greatest $>2.60 \mathrm{~kg} /$ $\mathrm{d}$. The most frequent range is 1.60 to $1.70 \mathrm{~kg} / \mathrm{d}$.

take values were for animals that raked some feed out of the feeder. The greatest-value class in Figure 2 was greater than $2.60 \mathrm{~kg} / \mathrm{d}$; however, this class included four animals with daily feed intake values greater than $3.0 \mathrm{~kg} / \mathrm{d}$. The most frequent range for daily feed intake was between 1.60 and $1.70 \mathrm{~kg} / \mathrm{d}$, and the mean was 1.69 $\mathrm{kg} / \mathrm{d}$. Eighty-seven percent of the rams had daily feed intake between 1.30 and $2.10 \mathrm{~kg} / \mathrm{d}$.

The most frequent range for number of daily feeding events of rams was between 15 and 17 events. The mean was 16.6, and $90 \%$ of ram lambs had between 7 and 25 feeding events per day. Although the greatestvalue class in Figure 3 was greater than 37 events, there was one ram lamb with 45 feeding events per day.

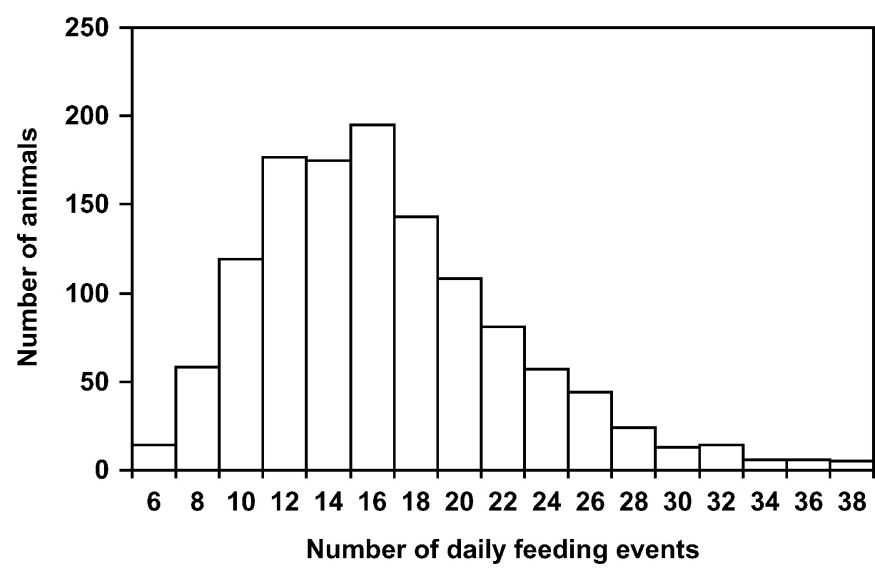

Figure 3. Distribution of number of daily feeding events or 1,239 ram lambs. Data are given in ranges of two events, with the least being five to seven events per day and the greatest $>37$ events per day. The most frequent range is 15 to 17 events per day.
Feed Intake Traits. The overall means for daily feed intake and event feed intake were $1.69 \mathrm{~kg}$ and $124.1 \mathrm{~g}$, respectively (Table 4). The CV for event feed intake $(37.4 \%)$ was much greater than that for daily feed intake $(17.1 \%)$. Direct heritabilities were moderate, with estimates of $0.25 \pm 0.06$ and $0.33 \pm 0.07$ for daily feed intake and event feed intake, respectively. Additionally, the difference in estimated heritabilities for event feed intake and daily feed intake implies that a greater behavioral component may be contributing to genetic variation in event feed intake than for daily feed intake.

The mean of residual feed intake is 0.00 ; thus, no CV is defined. In addition, because residual feed intake came from a model fitting contemporary groups, the contemporary group variance component was null, and therefore removed from the model. Estimated heritability for residual feed intake was $0.11 \pm 0.05$. Removing phenotypic variation in feed intake due to daily BW maintained and growth greatly decreased the fraction of variation due to direct genetic effects compared with daily feed intake.

Contrasts indicated that ram lambs produced by 1 yr-old dams had less daily feed intake and event feed intake than ram lambs produced by older dams. Differences were significant for both age of dam contrasts for daily feed intake and for the contrast of 1-yr-old vs. 3yr-old and older dams for event feed intake. Additionally, type of birth contrasts documented that single ram lambs had greater daily feed intake and event feed intake than either twin or triplet and greater ram lambs $(P<0.05)$. No age of dam or type of birth effects were detected for residual feed intake.

The heritability estimate of 0.25 for daily feed intake was at the lower end of estimates reported by Cameron (1988) for 341 Texel-Oxford ram lambs, which ranged from 0.14 to 0.59 and which were determined by various procedures. Gallivan and Sullivan (1994), using data collected on 766 ram lambs of several breeds, estimated heritability of daily feed intake of 0.66 . Francois et al. (2002) reported an estimated heritability of 0.43 for daily feed intake using data on 752 ram lambs of the INRA 401 breed. Snowder and Van Vleck (2003), using total feed intake over $98 \mathrm{~d}$ in a postweaning test for 952 Targhee ewe and ram lambs, estimated heritability to be 0.39 . Additionally, our heritability estimate tends to be lower than estimates for feed intake in cattle but similar to those in pigs. Archer et al. (1997) estimated heritability of feed intake to range from 0.56 to 0.65 in beef cattle. Foster et al. (1983) estimated heritability of feed intake for various breeds of swine, and reported an overall estimate (pooled over breeds) of 0.29. Finally, Johnson et al. (1999) estimated the heritability of feed intake for Large White pigs to be 0.23 .

Our estimate of heritability for residual feed intake (0.11) was considerably less than previous estimates for lambs. Francois et al. (2002) and Snowder and Van Vleck (2003) reported heritability estimates of residual feed intake in ram lambs of 0.30 and 0.26 , respectively. Estimates of heritability in beef cattle have fallen in a 
Table 4. Variance components, heritabilities, and contrasts of fixed effects from analyses of single traits ${ }^{\mathrm{a}}$

\begin{tabular}{|c|c|c|c|c|c|c|c|}
\hline Item $^{b}$ & DFI, kg & EFI, g & RFI, kg & DFT, min & EFT, min & $\mathrm{DFE}$ & $\mathrm{ADG}, \mathrm{g}$ \\
\hline$\sigma_{\mathrm{a}}^{2}$ & 0.020 & 662.5 & 6.69 & 148.96 & 2.49 & 10.93 & 1,504 \\
\hline$\sigma_{\mathrm{c}}^{2}$ & 0.011 & 407.4 & - & 36.66 & 2.71 & 6.87 & 1,808 \\
\hline$\sigma_{\mathrm{e}}^{2}$ & 0.049 & 948.5 & 56.81 & 223.66 & 3.43 & 13.66 & 2,385 \\
\hline$\sigma_{\mathrm{p}}^{2}$ & 0.080 & 2018.4 & 63.49 & 409.28 & 8.63 & 31.46 & 5,697 \\
\hline $\mathrm{h}_{\mathrm{a}}^{2}$ & $0.25 \pm 0.06$ & $0.33 \pm 0.07$ & $0.11 \pm 0.05$ & $0.36 \pm 0.08$ & $0.29 \pm 0.06$ & $0.35 \pm 0.07$ & $0.26 \pm 0.06$ \\
\hline$c^{2}$ & $0.14 \pm 0.03$ & $0.20 \pm 0.03$ & - & $0.09 \pm 0.02$ & $0.31 \pm 0.04$ & $0.22 \pm 0.03$ & $0.32 \pm 0.04$ \\
\hline $\mathrm{e}^{2}$ & $0.61 \pm 0.06$ & $0.47 \pm 0.06$ & $0.89 \pm 0.05$ & $0.55 \pm 0.06$ & $0.40 \pm 0.06$ & $0.43 \pm 0.06$ & $0.42 \pm 0.05$ \\
\hline$\overline{\mathrm{x}}$ & 1.69 & 124.1 & 0.00 & 118.3 & 8.54 & 16.6 & 418 \\
\hline $\mathrm{SD}$ & 0.29 & 46.38 & 7.94 & 20.27 & 3.07 & 5.83 & 81 \\
\hline $\begin{array}{l}\mathrm{CV}, \% \\
\mathrm{AOD}\end{array}$ & 17.1 & 37.4 & - & 17.1 & 36.0 & 35.1 & 19.3 \\
\hline $1-2$ & $-0.11^{*}$ & -6.8 & 0.13 & - & -0.04 & -0.51 & -4 \\
\hline $\begin{array}{l}1-3+ \\
\text { TOB }\end{array}$ & $-0.15^{*}$ & $-11.3^{*}$ & 0.41 & - & -0.30 & -0.37 & -7 \\
\hline $1-2$ & $0.10^{*}$ & $17.4^{*}$ & -0.64 & - & $0.93^{*}$ & $-1.10 *$ & 5 \\
\hline $1-3+$ & $0.13^{*}$ & $20.4^{*}$ & -1.06 & - & $1.00 *$ & -0.78 & 6 \\
\hline
\end{tabular}

wider range. Australian studies by Arthur et al. (1997) and Archer et al. $(1997,1998)$ reported estimates of heritability ranging from 0.34 to 0.64 . European studies of Brelin and Brännäng (1982) and Herd and Bishop (2000) reported heritability between 0.08 and 0.36 , and North American scientists (Koch et al. [1963] and Fan et al. [1995]) published estimates of heritability for residual feed intake between 0.14 and 0.28 .

\section{Feeding Behavior Traits}

The mean daily feeding time was $118.3 \mathrm{~min}$, and the mean event feeding time was 8.54 min (Table 4). The standard deviations for daily feeding time and event feeding time were $20.3 \mathrm{~min}$ and $3.07 \mathrm{~min}$, respectively. The CV on a per-event basis $(36.0 \%)$ was greater than on a per-day basis $(17.1 \%)$. The mean daily feeding time with ram lambs grouped 11 per pen and nine per pen was $113.9 \mathrm{~min}$ and $121.6 \mathrm{~min}$, respectively. On average for 11 ram lambs per pen, feeders were occupied 1,253 $\mathrm{min} / \mathrm{d}(11 \times 113.9)$ or $87 \%$ of the day (approximately 21 h). With nine ram lambs per pen, feeders were occupied $1,094 \mathrm{~min} / \mathrm{d}(9 \times 121.6)$ or $76 \%$ of the day. Estimates of direct heritabilities were $0.36 \pm 0.08$ and $0.29 \pm 0.06$ for daily feeding time and event feeding time, respectively.

Contrasts for age of dam were not significant for event feeding time. Single ram lambs spent significantly greater amounts of time feeding per event than twin or triplet and greater ram lambs.

The mean daily feeding time for these rams tended to be greater than averages for group-housed pigs. Averages for daily feeding time for group-housed pigs were estimated at 57.0 (de Haer et al., 1993), 62.5 (de Haer and de Vries, 1993), 63.5 (de Haer and Merks, 1992), and $78 \mathrm{~min}$ (Hyun et al., 1997). In addition, the mean event feeding time (8.54 min) in our study was greater than results for group-housed pigs. Estimates for average event feeding time for group-housed pigs ranged from 3.9 (de Haer et al., 1993) to $6.5 \mathrm{~min} /$ event (Hyun et al., 1997). The extent to which differences in digestive tract and possibly behavior between sheep and pigs influence true differences in feeding time between these species is unknown.

Number of feeding events per day had a mean of 16.6 and a standard deviation of 5.83. The CV was $35.1 \%$, a result of the feeding environment in which access was limited to one ram lamb at a time. Interactions between a ram lamb in the chute with those awaiting access may increase or decrease the number of events. The estimated direct heritability of number of daily feeding events was $0.35 \pm 0.07$.

Contrasts indicated that age of dam effects on number of daily feeding events were not significant, whereas multiple-born ram lambs visited the feeder more often than single-born ram lambs. The difference between single and twin ram lambs was significant.

The average number of daily feeding events (16.6) fell within the range of literature estimates for grouphoused animals. de Haer and de Vries (1993) reported group-housed pigs to average 16.2 feeding events per day. In additional studies, pigs in group-housing situations visited feeders an average of 14.4 (de Haer and Merks, 1992) and 18.0 (de Haer et al., 1993) times per day. 
Table 5. Genetic and phenotypic correlation estimates from two-trait analyses ${ }^{\mathrm{a}}$

\begin{tabular}{lccccr}
\hline \hline Trait $^{\mathrm{b}}$ & DFI & RFI & DFT & DFE & \multicolumn{1}{c}{ ADG } \\
\hline DFI & & $0.61 \pm 0.15$ & $0.26 \pm 0.16$ & $0.28 \pm 0.16$ & $0.80 \pm 0.10$ \\
RFI & 0.61 & $0.22 \pm 0.22$ & $0.20 \pm 0.22$ & $-0.03 \pm 0.20$ \\
DFT & 0.09 & 0.10 & $0.55 \pm 0.11$ & $0.17 \pm 0.14$ \\
DFE & 0.14 & 0.10 & 0.25 & & $0.31 \pm 0.15$ \\
ADG & 0.50 & 0.04 & 0.09 & 0.22 & \\
\hline
\end{tabular}

${ }^{\mathrm{a}}$ Genetic correlation estimates are above the diagonal, and phenotypic correlations are below the diagonal.

${ }^{\mathrm{b}} \mathrm{DFI}=$ daily feed intake; RFI = residual feed intake; DFT = daily feeding time; DFE = number of daily feeding events.

\section{Average Daily Gain}

Average daily gain had a mean of $418 \mathrm{~g}$ and a standard deviation of $81 \mathrm{~g}$. The direct heritability of ADG was moderate, with an estimate of $0.26 \pm 0.06$. Contrasts indicated that ram lambs with older dams and single-born ram lambs had an increased ADG; however, effects of age of dam and type of birth on ADG were not significant.

The heritability estimate of 0.26 tended to be lower than literature estimates for ADG. Boujenane and Kerfal (1990) estimated the heritability of ADG in D'man lambs from 30 to $90 \mathrm{~d}$ at 0.56. Mavrogenis et al. (1980) estimated heritability at 0.56 for ADG from $35 \mathrm{~d}$ to 20 wk of age in a population of Chios lambs. Heritability of ADG from 50 to $100 \mathrm{~d}$ of age was estimated at 0.50 in Dorset lambs by Shrestha et al. (1986). Additionally, Shrestha et al. (1985) estimated the heritability of ADG from 50 to $100 \mathrm{~d}$ in Suffolk lambs at 0.43. Mousa et al. (1999) analyzed ADG in this same composite breed of sheep using both ram and ewe lambs; heritability estimates were 0.16 and 0.23 , respectively. Using data on Targhee lambs over a 98-d test period, Snowder and Van Vleck (2003) estimated heritability as 0.39 for ADG, and Francois et al. (2002) estimated heritability of 0.43 for a $56-d$ postweaning test period.

\section{Multiple-Trait Analyses}

Two-trait analyses were performed for daily feed intake, residual feed intake, daily feed intake, number of daily feeding events, and ADG (Table 5). The genetic correlation between daily feed intake and ADG was 0.80 . This estimate agrees with the genetic correlation estimate of 0.83 in sheep by Francois et al. (2002) over a 56-d period and a somewhat greater value of 0.92 by Snowder and Van Vleck (2003) over a 98-d period, and estimates of $0.73,0.70$, and 0.71 reported by MacNeil et al. (1991), Archer et al. (1998), and Jensen et al. (1992), respectively, in beef cattle. The phenotypic correlation between daily feed intake and ADG was 0.50. Extrapolation from components provided in Snowder and Van Vleck (2003) yields a phenotypic correlation of 0.72. MacNeil et al. (1991), Archer et al. (1998), and Jensen et al. (1992) reported phenotypic correlations of $0.65,0.59$, and 0.33 , respectively.

The phenotypic correlation between residual feed intake and ADG was approximately zero (0.04), as would be expected. A point of interpretation of residual feed intake, calculated as the deviation from phenotypic regression of feed intake on BW maintained and gain as part of possible selection criteria, is that the genetic correlation between residual feed intake and ADG (and BW) may not be zero (Kennedy et al., 1993). The present estimate was essentially zero $(-0.03)$, which agrees with the estimate (0.00) by Francois et al. (2002) but not with the estimate (0.29) of Snowder and Van Vleck (2003), both with sheep.

The genetic correlation between daily feed intake and daily feeding time was 0.26 . The phenotypic correlation was 0.09. Hyun et al. (1997) reported a somewhat greater phenotypic correlation (0.25) between these traits in swine. The genetic correlation between daily feed intake and number of daily feeding events was 0.28 . The phenotypic correlation was 0.14 . These results imply that ram lambs that visit the feeder more often and spend more time feeding on a daily basis also have greater daily feed intake. In contrast, Hyun et al. (1997), working with swine data, reported a negative $(-0.28)$ rather than low positive phenotypic correlation between number of daily feeding events and daily feed intake. This might reflect a difference between species, but neither correlation is large or estimated precisely. Estimates of genetic and phenotypic correlations for residual feed intake with number of daily feeding events and daily feeding time were quite similar to those for daily feed intake with number of daily feeding events and daily feeding time.

The genetic correlation between number of daily feeding events and daily feeding time was estimated as 0.55 . The phenotypic correlation was also positive, with an estimate of 0.25 . This value is similar to an estimated phenotypic correlation in swine (0.17) reported by Hyun et al. (1997). Genetic and phenotypic correlations between number of daily feeding events and ADG were 0.31 and 0.22 , respectively. Ram lambs that visited the feeder more often had an increased ADG. The genetic correlation estimate between daily feeding time and $\mathrm{ADG}$ was 0.17 . The phenotypic correlation between these variables was 0.09 . Genetic correlations of these magnitudes suggest that a change made in one of these traits will lead to little change in the other.

In general, genetic correlations between measures of feed intake (daily feed intake and residual feed intake) and feeding behavior (daily feeding time and number 
of daily feeding events) and between growth (ADG) and feeding behavior were in the range of 0.20 and 0.30 ; for phenotypic correlations between these same sets of traits, the range was 0.10 to 0.20 .

Although feed intake should be considered in the selection objective for sheep even if not measured (James, 1986), there were no published estimates of heritability of feed intake when this research was started in 1986. This situation likely was due to the labor and facilities required to measure feed intake of individually penned sheep. Since then, electronic collection of feed data for individual sheep in a group setting has become feasible for research purposes.

In addition to the present results, several useful estimates of genetic parameters involving feed intake and ADG have now been published (Gallivan and Sullivan, 1994; Francois et al., 2002; Snowder and Van Vleck, 2003). One common characteristic is the similar values of heritability estimates for feed intake and ADG within each experiment, providing evidence that feed intake is genetically determined to the same degree as $\mathrm{ADG}$. Estimated heritabilities of these two traits range from about 0.25 to 0.45 , being quite consistent within experiment. Another characteristic is the similar values of estimated genetic correlations between feed intake and ADG across experiments, with values ranging from 0.80 to 0.92 .

These recent experimental results jointly provide a sound basis for development of selection indices that improve conversion of feed into ADG. Inclusion of feed intake into the selection objective seems more relevant for development of terminal sire breeds, where potential correlated responses in reproductive traits and maintenance costs are less a concern, than for maternal and general purpose breeds. Accordingly, correlated responses in carcass leanness due to changes in selection emphasis on feed intake and ADG should be investigated.

\section{Implications}

One approach to increase profitability of sheep production is to improve conversion of feed into weight gain. Understanding the role of genetics in feed intake and growth rate is necessary to select sheep that are genetically superior for feed conversion. Approximately $25 \%$ of the variation in feed intake and in growth rate is genetically determined. Genes that increase growth rate also increase feed intake to a large extent. Therefore, it will be a challenge to develop selection procedures that have favorable outcomes, such as increasing growth rate without increasing feed intake. Sheep with greater feed intake and growth rate tend to eat more meals per day and spend more time eating.

\section{Literature Cited}

Archer, J. A., P. F. Arthur, R. M. Herd, P. F. Parnell, and W. S. Pitchford. 1997. Optimum postweaning test for measurement of growth rate, feed intake, and feed efficiency in British breed cattle. J. Anim. Sci. 75:2024-2032.

Archer, J. A., P. F. Arthur, R. M. Herd, and E. C. Richardson. 1998. Genetic variation in feed efficiency and its component traits. Proc. 6th World. Congr. Genet. Appl. Livest. Prod., Armidale, Australia. 25:81-84.

Arthur, P. F., J. A. Archer, R. M. Herd, E. C. Richardson, S. C. Exton, J. H. Wright, K. C. P. Dibley, and D. A. Burton. 1997. Assoc. Advmt. Anim. Breed. Genet. 12:234-237.

Boldman, K. G., L. A. Kriese, L. D. Van Vleck, C. P. Van Tassell, and S. D. Kachman. 1995. A manual for use of MTDFREML. ARS, USDA, Clay Center, NE.

Boujenane, I., and M. Kerfal. 1990. Estimates of genetic and phenotypic parameters for growth traits of D'man lambs. Anim. Prod. 551:173-178.

Brelin, B., and E. Brännäng. 1982. Phenotypic and genetic variation in feed efficiency of Growing cattle and their relationship with growth rate, carcass traits and metabolic efficiency. Swedish J. Agric. Res. 12:29-34.

Cameron, N. D. 1988. Genetic relationships between growth and food intake in performance tested ram lambs: An investigation of variance component estimation procedures. J. Anim. Breed. Genet. 105:431-440.

de Haer, L. C. M., and A. G. de Vries. 1993. Feed intake patterns of and feed digestibility in growing pigs housed individually or in groups. Livest. Prod. Sci. 33:277-292.

de Haer, L. C. M., P. Luiting, and H. L. M. Aarts. 1993. Relations among individual (residual) feed intake, growth performance and feed intake pattern of growing pigs in group housing. Livest. Prod. Sci. 36:233-253.

de Haer, L. C. M., and J. W. M. Merks. 1992. Patterns of daily food intake in growing pigs. Anim. Prod. 54:95-104.

Fan, L. Q., D. R. C. Bailey, and N. H. Shannon. 1995. Genetic parameter estimation of post-weaning gain, feed intake, and feed efficiency for Hereford and Angus bulls fed two different diets. J. Anim. Sci. 73:365-372.

Foster, W. H., D. J. Kilpatrick, and I. H. Heaney. 1983. Genetic variation in the efficiency of energy utilization by the fattening pig. Anim. Prod. 37:387-393.

Francois, D., D. Bibe, J. B. Brunel, J. L. Weisbecker, and E. Ricard. 2002. Genetic parameters of feeding traits in meat sheep. Proc. 7th World Congress Gen. Appl. Livest. Prod., Montpellier, France. CD-ROM Communication 10:10.

Gallivan, C., and P. G. Sullivan. 1994. Selection criteria for terminal sires of Ontario lambs. Proc. 5th World. Congr. Genet. Appl. Livest. Prod., Guelph, Canada. 18:47-50.

Herd, R. M., and S. C. Bishop. 2000. Genetic variation in residual feed intake and its association with other traits in British Hereford cattle. Livest. Prod. Sci. 63:111-119.

Hyun, Y., M. Ellis, F. K. McKeith, and E. R. Wilson. 1997. Feed intake pattern of group-housed growing-finishing pigs monitored using a computerized feed intake recording system. J. Anim. Sci. 75:1443-1451.

James, J. J. 1986. Economic evaluation of breeding objectives in sheep and goats-General considerations. 3rd World Congr. Genet. Appl. Livest. Prod., Lincoln, NE. IX:470-478.

Jenkins, T. G., and K. A. Leymaster. 1987. Feeding behavior characteristics of intact male lambs as affected by number of lambs in a pen with restricted access to the feed stall. J. Anim. Sci. 65:422-430.

Jensen, J., I. L. Mao, B. Bech Andersen, and P. Madsen. 1992. Phenotypic and genetic relationships between residual energy intake and growth, feed intake, and carcass traits of young bulls. J. Anim. Sci. 70:386-395.

Johnson, Z. B., J. J. Chewning, and R. A. Nugent, III. 1999. Genetic parameters for production traits and measures of residual feed in Large White swine. J. Anim. Sci. 77:1679-1685.

Kennedy, B. W., J. H. J. van der Werf, and T. H. E. Meuwissen. 1993. Genetic and statistical properties of residual feed intake. J. Anim. Sci. 71:3239-3250. 
Koch, R. M., L. A. Swiger, D. Chambers, and K. E. Gregory. 1963. Efficiency of feed use in beef cattle. J. Anim. Sci. 22:486-494.

Leymaster, K. A. 1991. Straightbred comparison of a composite population and the Suffolk breed for performance traits of sheep. J. Anim. Sci. 69:993-999.

MacNeil, M. D., D. R. C. Bailey, J. J. Urick, R. P. Gilberg, and W. L. Reynolds. 1991. Heritabilities and genetic correlations for postweaning growth and feed intake of beef bulls and steers. J. Anim. Sci. 69:3183-3189.

Mavrogenis, A. P., A. Louca, and O. W. Robison. 1980. Estimates of genetic parameters for pre-weaning and post-weaning growth traits of Chios lambs. Anim. Prod. 30:271-276.
Mousa, E., L. D. Van Vleck, and K. A. Leymaster. 1999. Genetic parameters for growth traits for a composite terminal sire breed of sheep. J. Anim. Sci. 77:1659-1665.

Shrestha, J. N. B., J. A. Vesely, and J. P. Chesnais. 1985. Genetic and phenotypic parameters for daily gain and body weights in Suffolk lambs. Can. J. Anim. Sci. 65:575-582.

Shrestha, J. N. B., J. A. Vesely, J. P. Chesnais, and D. Cuthbertson. 1986. Genetic and phenotypic parameters for daily gain and body weights in Dorset lambs. Can. J. Anim. Sci. 66:289-292.

Snowder, G. D., and L. D. Van Vleck. 2003. Estimates of genetic parameters and selection strategies to improve the economic efficiency of postweaning growth in lambs. J. Anim. Sci. 81:2704-2713. 